\title{
Novas formas de organização rural: os Condomínios de Armazéns Rurais
}

\author{
New forms of rural organization: the Rural Warehouse \\ Condominiuns
}

\author{
Amanda Cristina Gaban Filippi ${ }^{1}$ (D) e Patricia Guarnieri ${ }^{1}$
}

\begin{abstract}
Resumo: Com o desenvolvimento do setor agrícola no país e mudanças políticas, econômicas e sociais, o Brasil se tornou um dos principais produtores e exportadores de commodities no Agronegócio. Adicionalmente, os gargalos logísticos, principalmente o relacionado ao déficit de armazenagem, bem como o crescente interesse no Supply Chain Management e nas novas formas de organização rural ganharam importância para as cadeias produtivas. O objetivo desse artigo é caracterizar a nova forma de organização rural denominada de Condomínios de Armazéns Rurais. Realizou-se uma pesquisa aplicada, exploratória e descritiva, com procedimento técnico de estudo Multicaso, complementado pela revisão da literatura. A coleta de dados ocorreu por meio de entrevistas, observação direta e análise documental. Constatou-se que esta nova configuração é um modelo em expansão, viável e financeiramente competitivo para o agronegócio brasileiro, que proporcionam a diminuição do déficit de armazenagem e outros gargalos logísticos. Ademais, apresentam inúmeras vantagens, como a comercialização estratégica da produção, a redução de custos de armazenagem e de custos logísticos e o aumento do lucro para os associados. Este trabalho contribui ao mapear práticas inovadoras no setor de armazenagem e propõe uma agenda de pesquisa que pode auxiliar acerca do tema abordado.
\end{abstract}

Palavras-chave: armazenagem, associação rural, condomínios de armazéns rurais, logística agroindustrial.

Abstract: Considering the development of the agricultural sector in the country and political, economic and social changes, Brazil became one of the main producers and exporters of commodities in agribusiness. In addition, the logistical bottlenecks, especially the shortage in the warehousing, as well as the growing interest in Supply Chain Management and new forms of rural organization have gained importance for the productive chains. The objective of this article is to characterize the new rural organization called Rural Warehouse Condominiums. For this purpose, an applied, exploratory

Data de submissão: 26 de março de 2017. Data de aceite: 18 de junho de 2018.

1. Universidade de Brasília, Brasília (DF), Brasil. E-mail: amandagaban@hotmail.com; profpatriciaunb@gmail.com 
and descriptive research was carried out with the use of multiple case studies and literature review. The data collection was conducted through interviews, direct observations and documental analysis. It was verified that this new configuration is an expanding, viable and financially competitive model for the Brazilian agribusiness, which provides the reduction of the storage deficit and other logistics bottlenecks. In addition, they present innumerable advantages, such as the strategic commercialization of production, the reduction of storage costs and logistic costs and the increase of profit. This work contributes to the mapping of innovative practices in the storage sector and proposes a research agenda that can help on the topic.

Key-words: warehouse, rural association, rural warehouse condominiums, agroindustrial logistic.

Classificação JEL: Q13.

\section{Introdução}

Com o desenvolvimento do setor agrícola no País, o Brasil se tornou um dos principais países produtores e exportadores de commodities no agronegócio, apresentando constantes aumentos na produção e na produtividade dos principais produtos agrícolas, com destaque para grãos (soja e milho), os quais são direcionados para o mercado externo (Companhia Nacional de Abastecimento, 2017). Junto a esse cenário, expressivas mudanças políticas, econômicas e sociais, geradas pelo mercado globalizado, pela revolução tecnológica, pela concorrência acirrada, dentre outros aspectos, conduzem as organizações rurais para o desenvolvimento de novas formas de governança baseadas nos princípios da coletividade e na cooperação agrícola, com o intuito de obter competitividade (Wenningkamp \& Schmidt, 2016; Zylbersztajn, 2017).

Entretanto, existem diversos fatores que devem ser aperfeiçoados no sistema da produtividade da logística agroindustrial no Brasil, na distribuição para escoamento da produção, principalmente no que tange às atividades de transporte e armazenagem. Estas atividades contribuem para que o País não perca mercado externo e ganhe mais competitividade entre países produtores concorrentes, de forma a obter crescimento e desenvolvimento econômico (Gaban \& Guarnieri, 2015; Nogueira Junior \& Tsunechiro, 2005; Oliveira, 2011). Ménard \& Klein (2004) complementam que agricultores e participantes da cadeia de suprimentos tornaram-se cada vez mais importantes em diversas partes do mundo, evidenciando a necessidade de pesquisas relacionadas ao conceito de
Supply Chain Management, bem como a atenção que novos Journals dão ao tema e aos novos modos de organização rural não padronizados que têm surgindo no segmento de agronegócios.

Adicionalmente, ressalta-se a necessidade de uma logística de distribuição adequada e eficiente para o escoamento da produção de commodities agrícolas, caracterizada no Brasil por possuir inúmeros gargalos (Caixeta-Filho, 2006). Referente à armazenagem, destaca-se o déficit existente no País, tanto no setor privado como público. Apesar de a produção e produtividade dos produtos agrícolas aumentarem a cada safra, o setor de armazenagem não tem acompanhado o mesmo ritmo de crescimento, o que ocasiona que volumes significativos da produção deixem de ser armazenados em locais adequados (Companhia Nacional de Abastecimento, 2017; Filippi, 2017).

Diante desse cenário e com o intuito de superar o déficit de armazenagem e outros gargalos logísticos (Gaban \& Guarnieri, 2015), bem como reduzir custos desnecessários e obter vantagens do sistema de armazenagem e do sistema condominial, agricultores rurais vizinhos começaram a se organizar na forma de Condomínios de Armazéns Rurais (Filippi, 2017).

Como a temática sobre os Condomínios Rurais é relativamente nova, pertinente para o agronegócio brasileiro e pouco abordada na literatura (Almeida et al., 2017; Anjos et al., 2011; Filippi, 2017; Gullo, 2001; Moyano-Estrada \& Anjos, 2001; Olivo, 2000), evidencia-se a necessidade de pesquisas científicas relacionadas ao tema (Filippi, 2017). Portanto, o objetivo desse trabalho é caracterizar 
os Condomínios de Armazéns Rurais, que se configuram como uma nova forma de organização rural.

Para tanto, foi realizada uma pesquisa aplicada, exploratória e descritiva, qualitativa e que utilizou como procedimento técnico o estudo de casos múltiplos. Foram estudados três condomínios já consolidados nos estados do Paraná e Rio Grande do Sul. Para a coleta de dados foram utilizadas a entrevista semiestruturada, a análise documental e a observação direta. A análise de dados ocorreu por meio da técnica de análise categorial temática proposta por Bardin (1977), com a construção de categorias a priori.

Dos principais resultados encontrados, com base na discussão das principais vantagens e desafios enfrentados por essa nova forma de organização rural, destacam-se como vantagens: a redução do déficit de armazenagem e outros gargalos logísticos que os Condomínios de Armazéns proporcionam, a comercialização estratégica da produção, a redução de custos de armazenagem e logísticos, e o aumento do lucro para os associados. Como desafios destacam-se a necessidade de políticas públicas de incentivo ao financiamento desse tipo de estruturas, a falta de planejamento formal para sua estruturação. Este trabalho contribui ao mapear práticas inovadoras no setor de armazenagem e propõe uma agenda de pesquisa que pode auxiliar acerca do tema abordado.

\section{Fundamentação teórica}

\subsection{Desafios da Logística Agroindustrial Brasileira: o setor de armazenagem}

Nos últimos anos, os produtos agrícolas ganharam importância entre as principais atividades econômicas, auxiliando o País a manter-se competitivo e a ganhar mercado externo entre os principais países concorrentes (Filippi, 2017). Com quase metade das exportações brasileiras representadas pelos produtos agrícolas (Brasil, 2017), a logística de distribuição, representada pelo transporte e pela armazenagem, atuam no seu devido escoamento (Gaban \& Guarnieri, 2015).

De acordo com Brigatte \& Teixeira (2011) e Barreto \& Almeida (2009) a infraestrutura e a logística, principalmente em sua atividade de armazenagem, são elementos relevantes para o agronegócio brasileiro. A armazenagem agrícola é considerada determinante para o crescimento econômico (Brigatte \& Teixeira, 2011) e condição para o crescimento do PIB per capita agropecuário (Barreto \& Almeida, 2009). Na Tabela 1, este cenário é apresentado.

Com base na Tabela 1, percebe-se que a balança comercial do agronegócio tem expressiva representatividade na balança comercial brasileira, tendo participação de 46,2\% em 2015 e de 45,9\% em 2016. Aliado a esse fato, o saldo da balança comercial brasileira mostra-se positivo nesse período, com US\$ 75,15 bilhões em 2015 e US\$ 71,31 bilhões em 2016.

Contudo, o País sofre com inúmeros gargalos logísticos no setor de distribuição, entre eles o déficit no setor de armazenagem (Martins et al., 2014; Companhia Nacional de Abastecimento, 2017; Filippi, 2017) e a necessidade de adequação das unidades armazenadoras já existentes, as quais se encontram em estado precário (Oliveira, 2011). Tais fatores comprometem o escoamento logístico eficiente e eficaz da produção agrícola, prejudicando o crescimento e desenvolvimento do País (Gaban \& Guarnieri, 2015; Companhia Nacional de Abastecimento, 2017; Filippi, 2017; Nogueira Junior \& Tsunechiro, 2005; Oliveira, 2011). Segundo, Guarnieri \& Hatakeyama (2010), os elos e atividades da logística precisam funcionar de maneira coordenada e integrada. Dessa forma, a logística pode garantir plena eficiência e otimização dos resultados

Tabela 1. Balança comercial brasileira (a) e balança comercial do agronegócio (b)

\begin{tabular}{|c|c|c|c|c|c|c|}
\hline \multicolumn{7}{|c|}{ Acumulado entre janeiro e dezembro de 2015 e 2016} \\
\hline \multirow{2}{*}{ Balança/Ano } & \multicolumn{2}{|c|}{ Exportação (US\$ bilhões) } & \multicolumn{2}{|c|}{ Importação (US\$ bilhões) } & \multicolumn{2}{|c|}{ Saldo } \\
\hline & 2015 & 2016 & 2015 & 2016 & 2015 & 2016 \\
\hline Total Brasil (a) & 191,13 & 185,23 & 171,45 & 17,55 & 19,68 & 47,68 \\
\hline Demais Produtos & 102,91 & 100,30 & 158,37 & 123,92 & $-55,46$ & $-23,62$ \\
\hline Agronegócio (b) & 88,22 & 84,93 & 13,07 & 13,62 & 75,15 & 71,31 \\
\hline Participação (\%) & 46,2 & 45,9 & 7,6 & 9,9 & - & - \\
\hline
\end{tabular}

Fonte: Adaptado de AgroStat Brasil a partir de dados do Mapa/Secex/Mdic (Brasil, 2017). 
operacionais (Weil, 1975). Quanto ao foco desse trabalho, a Figura 1 evidencia a evolução da produção de grãos e da capacidade de armazenagem.

De acordo com a Figura 1, verifica-se que, nos últimos 15 anos, o País sofreu com déficit de armazenagem em todo período, sendo que, na safra 2016/17, a expectativa é de que $26,71 \%$ da produção de grãos fique sem local adequado para ser armazenada (Companhia Nacional de Abastecimento, 2017). Isto significa que 57,5 milhões de toneladas de grãos que serão produzidos deixarão de ser armazenados e as vantagens proporcionadas pela armazenagem não serão usufruídas.

Entre essas vantagens estão a armazenagem estratégica (Alvarenga \& Novaes, 2000; Filippi, 2017) e comercialização estratégica da produção (Alvarenga \& Novaes, 2000; Filippi, 2017; Neves \& Conejero, 2007; Nogueira Junior \& Tsunechiro, 2005; Martins et al., 2005). A armazenagem estratégica proporciona que os produtos que possam sofrer com intempéries climáticas, pragas e doenças, bem como ocasionar quebras de safras ou redução, junto períodos de entressafra, possam ser estocados a fim de não ocasionar a falta do produto. Por sua vez, a comercialização estratégica da produção permite que a venda do produto armazenado seja realizada em qualquer época do ano, safra ou entressafra, a fim de obter melhores preços para o produto no mercado ou aguardar o momento mais oportuno para a venda da produção (Filippi, 2017).

Além disso, a armazenagem proporciona outras vantagens como: (i) a racionalização de custos de transporte e de comercialização (Biagi et al., 2002; Ferrari, 2006; Sasseron, 1995); (ii) melhora a conservação dos grãos (Sasseron, 1995); (iii) reduz os gargalos logísticos (Filippi, 2017); (iv) melhora e facilita o escoamento da safra (Gentil \& Martin, 2014); e (v) possibilita alugar as estruturas armazenadoras quando estiverem desocupadas (Filippi, 2017; Gentil \& Martin, 2014).

Complementarmente às idéias anteriores, Gentil \& Martin (2014) ressaltam a importância da armazenagem na própria unidade produtiva. Além de esta contribuir com a função estratégica da armazenagem e comercialização do produto, evitando que o produtor tenha problemas com variações de preços; permite melhor qualidade e menor perda; facilita o escoamento da safra; torna-se variedade de opção para a venda do produto; e possibilita produzir derivados, como ração.

De acordo com Figueiredo et al. (2003), a armazenagem representa um custo logístico de $21 \%$ em relação ao custo logístico total, sendo a segunda maior fonte de despesas logísticas, já que envolve a atividade de estocagem, estando apenas atrás dos custos de transportes, que representam $64 \%$ do custo logístico total. Já para Ballou (2011), o custo da armazenagem pode variar de 12 a 40\% das despesas logísticas de uma empresa, sendo que a armazenagem e o manuseio dos produtos e mercadorias são componentes essenciais do conjunto de atividades logísticas.

Adicionalmente, o cenário para os próximos anos seguirá essa mesma tendência se nada for alterado no setor de armazenagem, bem como o déficit de armazenamento

Figura 1. Evolução da produção de grãos versus evolução da capacidade de armazenamento

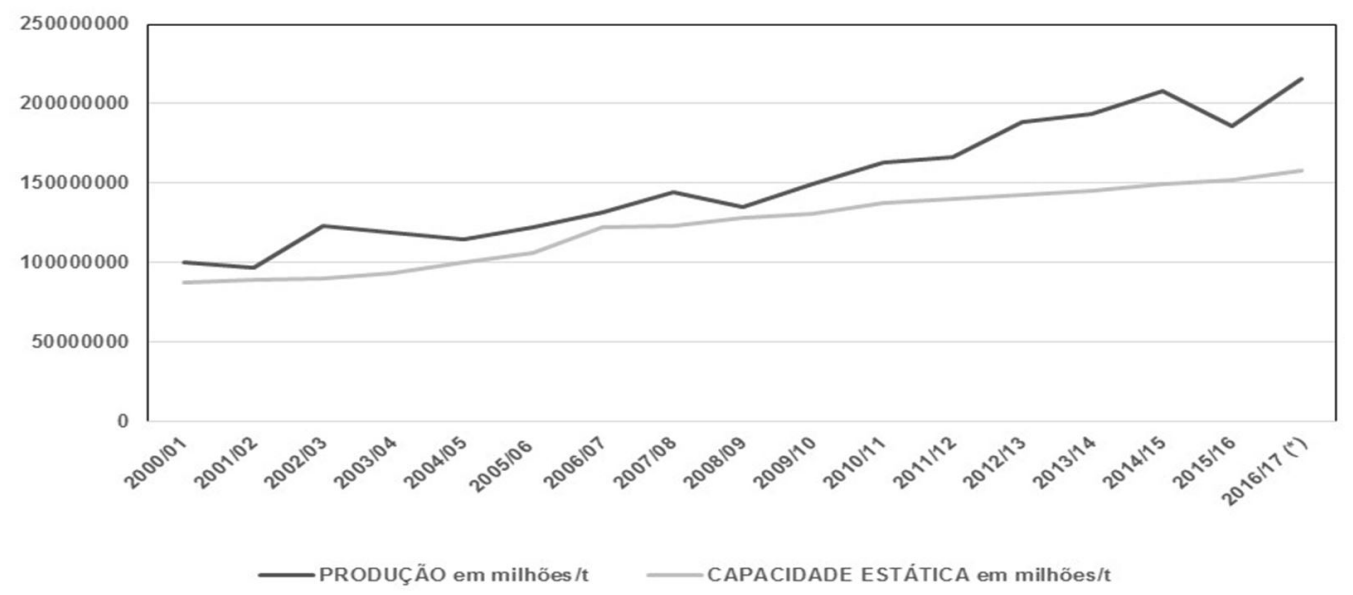

Fonte: Adaptado de Companhia Nacional de Abastecimento (2017).

* Previsão: Estimativa Janeiro/2017. 
poderá aumentar. De acordo com as projeções para o agronegócio brasileiro, no período compreendido entre 2000/01 a 2024/25, o País continuará a ter aumentos significativos na produção e produtividade de grãos (Companhia Nacional de Abastecimento, 2017; Brasil, 2015; Gaban et al., 2016). Percebe-se que a produção de grãos passará de 200,68 milhões de toneladas produzidas em 2014/ 15 para 259,74 milhões de toneladas na safra de $2024 / 25$. Isso significa aumento de $29,4 \%$ na produção, gerando, consequentemente, um aumento no déficit de armazenagem, que passará de $26,71 \%$ para $35,37 \%$.

Dessa forma, os dados apresentados evidenciam uma situação deficitária no setor de armazenagem para os produtos agrícolas, bem como uma perspectiva negativa para os próximos anos quanto ao escoamento e logística da produção de grãos, caso a situação permaneça estática.

\subsection{Novas formas de organização rural: os Condomínios de Armazéns Rurais}

Diante do cenário descrito anteriormente e no surgimento de novas formas de governança baseadas nos princípios da coletividade e na cooperação agrícola (Wenningkamp \& Schmidt, 2016), surge a nova configuração rural denominada de Condomínios de Armazéns Rurais (Filippi, 2017).

Os Condomínios de Armazéns Rurais são um tipo de organização associativista, empreendedora e relativamente nova, em que é viabilizada uma estrutura completa de armazenagem através da divisão de cotas de armazenamento entre produtores rurais vizinhos sócios. Além de auxiliar na superação do déficit de armazenagem, dentre outros gargalos logísticos como o de transporte, os condomínios reduzem custos e proporcionam vantagens com base no sistema condominial e da armazenagem (Filippi, 2017).

Tal modelo tem bases e características fortemente ligadas ao movimento associativista, conforme Filippi (2017) identificou sobre as principais motivações, características e aspectos importantes dos Condomínios de Armazéns Rurais com base no associativismo. Por sua vez, o associativismo é um tipo de movimento que objetiva unir forças entre produtores rurais para superar dificuldades da agricultura, fortalecer a propriedade e mantê-la competitiva diante dos demais concorrentes, através da viabilização das atividades econômicas e com o intuito que esses produtores participem num mercado competitivo (Brasil, 2017).
Ademais, constata-se que as pesquisas e estudos sobre os Condomínios de Armazéns Rurais são escassas e a maioria está em notícias, relatórios técnicos, reportagens televisivas e revistas, evidenciando a necessidade de pesquisas na área em periódicos científicos (Olivo, 2000; Filippi, 2017).

Nesse sentido, alguns estudos podem ser destacados. Olivo (2000) propôs um modelo de gestão baseado na sustentabilidade de Condomínios Rurais Leiteiros. Posteriormente, Moyano-Estrada \& Anjos (2001) e Anjos et al. (2011) analisaram as novas formas de cooperação econômica na agricultura familiar no estado de Santa Catarina com ênfase na criação de suínos e identificaram que existe expansão dos Condomínios Rurais para outros setores da agroindústria brasileira, bem como esse modelo tem potencial para tornar-se referência quanto ao incentivo de projetos coletivos e, dessa forma, garantir o desenvolvimento da sociedade rural. Já Gullo (2001) trabalhou com Condomínios Rurais de suínos e leiteiros. E por fim, Filippi (2017) caracterizou e analisou a viabilidade dos Condomínios de Armazéns Rurais com base em condomínios de armazéns rurais já consolidados nos estados do Paraná e Rio Grande do Sul, e Almeida et al. (2017) analisaram a viabilidade sócio-econômica para implantação de Condomínios de Agroenergia no oeste do Paraná.

Adicionalmente, um estudo recente de Wenningkamp \& Schmidt (2016) levantou a produção científica de dissertações e teses no Brasil sobre ações coletivas no agronegócio entre 1998 e 2012 e identificou que o número publicado sobre a temática é ainda relativamente baixo, bem como o tema é pertinente ao cenário e ações coletivas são estruturas de governança cada vez mais recorrentes para o agronegócio. Décio Zylbersztajn (2017) também corrobora com o apontado pelos autores quando afirma que, entre os temas de pesquisas relevantes para os estudos do agronegócio estão as ações coletivas.

Da mesma forma, Saes (2005) e Olson (1965) também relatam sobre a importância dos estudos sobre ações coletivas. Os autores exemplificam algumas vantagens das organizações coletivas para superar desafios e dificuldades, como a maximização do lucro dos associados, provisão de bens ou serviços e a melhor eficiência do negócio através de ações coletivas organizadas (Olson, 1965; Saes, 2005).

Percebe-se, que além de serem escassas as informações acadêmicas sobre o assunto de Condomínios Rurais no 
âmbito nacional, no setor de armazenagem especificamente, apenas uma pesquisa com enfoque logístico, mais especificamente relacionado à armazenagem, foi realizada recentemente (Filippi, 2017). Dessa forma, acredita-se que existe potencial para o desenvolvimento de novos trabalhos acadêmicos com Condomínios Rurais, principalmente no setor de armazenagem, no cenário da logística agroindustrial, para superar os desafios de infraestrutura existentes e de distribuição, reduzindo custos e tornar o produto agrícola mais competitivo.

\section{Procedimentos metodológicos}

De acordo com o proposto por Silva \& Menezes (2001), esta pesquisa é classificada como aplicada, exploratória, descritiva e qualitativa. Quanto aos procedimentos técnicos para atingir o objetivo da pesquisa, foi utilizado o estudo Multicaso, complementado pela revisão de literatura e análise documental. A revisão de literatura e análise documental trataram sobre: (i) o levantamento de informações a respeito dos desafios que existem no setor de armazenagem brasileiro, bem como um breve panorama da importância da logística para o agronegócio brasileiro; e (ii) a relevância do tema Condomínios de Armazéns Rurais na conjuntura da logística agroindustrial.

Com relação ao estudo de caso, objetivou levantar os dados acerca das vantagens e desafios dos Condomínios de Armazéns Rurais, e também teve o propósito de propor uma agenda de pesquisa sobre o tema. O estudo Multicaso foi realizado na região Sul do País, com três Condomínios de Armazéns Rurais já consolidados e pioneiros na implementação desse novo tipo de organização de produtores rurais. Dois deles localizam-se no estado do Paraná e o outro no Rio Grande do Sul. Adicionalmente, para garantir o sigilo da pesquisa e os dados pessoais dos produtores condôminos, os condomínios serão denominados como Condomínio A, Condomínio B e Condomínio C.

Por fim, a coleta de dados primários teve os seguintes instrumentos de pesquisa: (i) entrevista semiestruturada com gestores dos três condomínios; (ii) análise documental através de documentos internos cedidos pelas organizações estudadas; e (iii) a observação direta realizada durante a visitação nos condomínios, a qual ocorreu em novembro de 2016. Tais dados coletados foram analisados pela técnica de análise de conteúdo proposta por Bardin (1977), com a análise das falas dos entrevistados e núcleos de sentido dos textos, seguida por meio de três etapas: pré-análise, exploração do material e tratamento dos resultados. As categorias da análise foram definidas a priori.

\section{Resultados e discussão}

\subsection{Condomínios de Armazéns Rurais: uma breve caracterização}

Os Condomínios de Armazéns Rurais consistem em uma nova forma de organização rural, com características semelhantes ao associativismo, que surgiram com o intuito de superar os problemas advindos do déficit de armazenagem e de outros gargalos logísticos no setor de agronegócios, bem como obter as vantagens que o sistema de armazenagem condominial proporciona.

Geralmente, os condomínios são formados por produtores rurais vizinhos, que podem ter algum grau de parentesco ou não e constituem um modelo mais simplista se comparado a uma cooperativa, com 8 a 26 produtores sócios condôminos. Além disso, os produtores condôminos produzem, em grande parte, soja e milho como produtos principais, em áreas que variam entre 3.500 e 5.000 hectares, gerando produção de 224.000 a 840.000 sacas na safra. Aliado a isso, a capacidade estática disponível para o armazenamento desses produtos pode variar entre 180.000 a 450.000 sacas, número que pode variar a depender do tipo de condomínio. Pode ocorrer a ampliação caso percebido o déficit de armazenagem ou aumento na produção e produtividade dos condôminos, já que o custo para viabilizar essa ampliação é diluído entre todos os sócios.

Na fala de um dos entrevistados é possível observar a ideia da criação e estruturação do empreendimento (entrevistado C do Condomínio C). Além disso, percebe-se que uma das vantagens dessa organização proporciona a diluição dos custos para viabilizar uma estrutura completa de armazenagem, que seria inviável individualmente para esse perfil de produtor rural, considerando de menor a médio porte:

A ideia do condomínio surgiu por meio de produtores que já se conheciam há bastante tempo e todo mundo tinha vontade de ter uma estrutura para armazenar 
o produto próprio. Mas aí para você fazer, para cada um montar uma estrutura própria, fica bastante, fica bem mais caro, porque você não consegue fazer uma estrutura desse tamanho. Ena forma de condominio você consegue diluir os custos (entrevistado $C$ do Condomínio C).

Complementando essa vantagem, destaca-se que esses produtores rurais enfrentavam problemas logísticos de distribuição, conforme denota a fala do entrevistado B (Condomínio B):

Como é muito produtor e a região é pequena, quase que todo mundo colhe no mesmo dia, então teria que deixar o caminhão na fila ali o dia inteiro para descarregar uma carga só. Quando a gente monta o condomínio, ai acabou esse problema, porque aí a gente pode entregar, ofluxo de recebimento ébom, só nós que entregamos ali, não recebemos de terceiros, não tem fluxo de terceiros, a gente consegue planejar a colheita, "quando eu não colho, o meu sócio colhe, aí ele entrega mais", então isso facilitou uma série de situações pra gente.

Com base na fala do entrevistado B, percebem-se problemas logísticos de distribuição relativos principalmente à infraestrutura do transporte e da armazenagem que dificultavam e geravam perdas para os produtores rurais em relação ao escoamento da produção agrícola. Considera-se como problema também as filas geradas devido ao déficit em armazenagem e excesso de caminhões que chegavam nos armazéns e silos de terceiros para tentar armazenar sua produção, já que não dispunham de estrutura própria de armazenagem. Tal fato impelia esses produtores a permanecerem parados na entrada de silos e armazéns de terceiros aguardando a liberação do fluxo, que poderia durar o dia inteiro, impedindo o caminhão de retornar para a fazenda, em que poderia ser mais produtivo.

Por fim, alguns produtores notaram que possuir a própria estrutura de armazenagem renderia lucratividade maior, já que, se realizassem o armazenamento de seus produtos em estruturas de terceiros, seria descontado um percentual relativo da produção, ou seja, do lucro que obteriam. Junto a isso, a venda através dos Condomínios de Armazéns Rurais ocorria de forma direta, isto é, sem intermediários na comercialização do produto. Dessa forma, o valor total da venda ganha com a produção retornaria integralmente aos associados, nada seria descontado. A fala do entrevistado B denota esse aspecto:
Vendido através de outras empresas, de colhedoras, a gente não fica preso a ninguém, e isso agrega um pouco mais o valor do produto, pelo menos para tirar os custos que têm ali com armazenagem, de recebimento, de armazenagem.

A gente tem o custo que a gente não teria se entregasse para a cooperativa, tem esse custo também, mas a gente tem um lucro maior vendendo direto, não passando pelo atravessador - que seria a cooperativa - e esse lucro a gente consegue pagar os custos e ainda sobra alguma coisinha que é mais ou menos aquilo que a empresa ganha ou que a cooperativa ganharia com o nosso produto (entrevista do B, Condomínio B).

Nesse sentido, esses produtores rurais vizinhos começaram a se unir e juntar forças para viabilizar a estrutura de armazenagem, bem como obter vantagens do sistema condominial e do armazenamento estratégico.

Entre os principais componentes estruturais dos Condomínios de Armazéns Rurais existem: (i) conjunto de silos, que variam de acordo com a necessidade para armazenagem, podendo ser aumentado se necessário, conforme é mostrado em "área disponível"; (ii) prédio administrativo, que pode abrigar o escritório, salas menores, balcão de funcionários, alguns funcionários e os próprios clientes que vêm ao condomínio para comprar a produção armazenada ou parte dela; (iii) recepção e balança: local que recebe, pesa e faz a amostragem dos caminhões que transportam as cargas agrícolas (teor de impureza e umidade relativa dos produtos); (iv) galpões: estrutura que pode abrigar moegas, máquinas de limpeza, secador, tombador, fornalha etc., sendo responsável pelos procedimentos operacionais de descarga do produto dos caminhões na moega, pré-limpeza (separação de impureza mais grossa do produto melhor), secagem (milho), pós-limpeza (nova limpeza entre impurezas e do produto de melhor qualidade) e armazenamento no silo; (v) área disponível: área desocupada do condomínio que pode servir para futuras ampliações, construções de novos silos ou abrigar silo bags temporários em caso de emergências de armazenagem; e (vi) área agrícola.

A Figura 2 exemplifica com fotos reais as estruturas físicas de um dos condomínios do estudo.

A Figura 2 apresenta os seguintes componentes: (1) recepção do condomínio, prédio administrativo e balança; (2) e (3) vista geral dos silos e galpão; (4) vista de dentro do galpão, com a entrada de um caminhão no momento em que ele recebe o produto para escoar; 
Figura 2. Estrutura física do Condomínio de Armazém Rural (A)

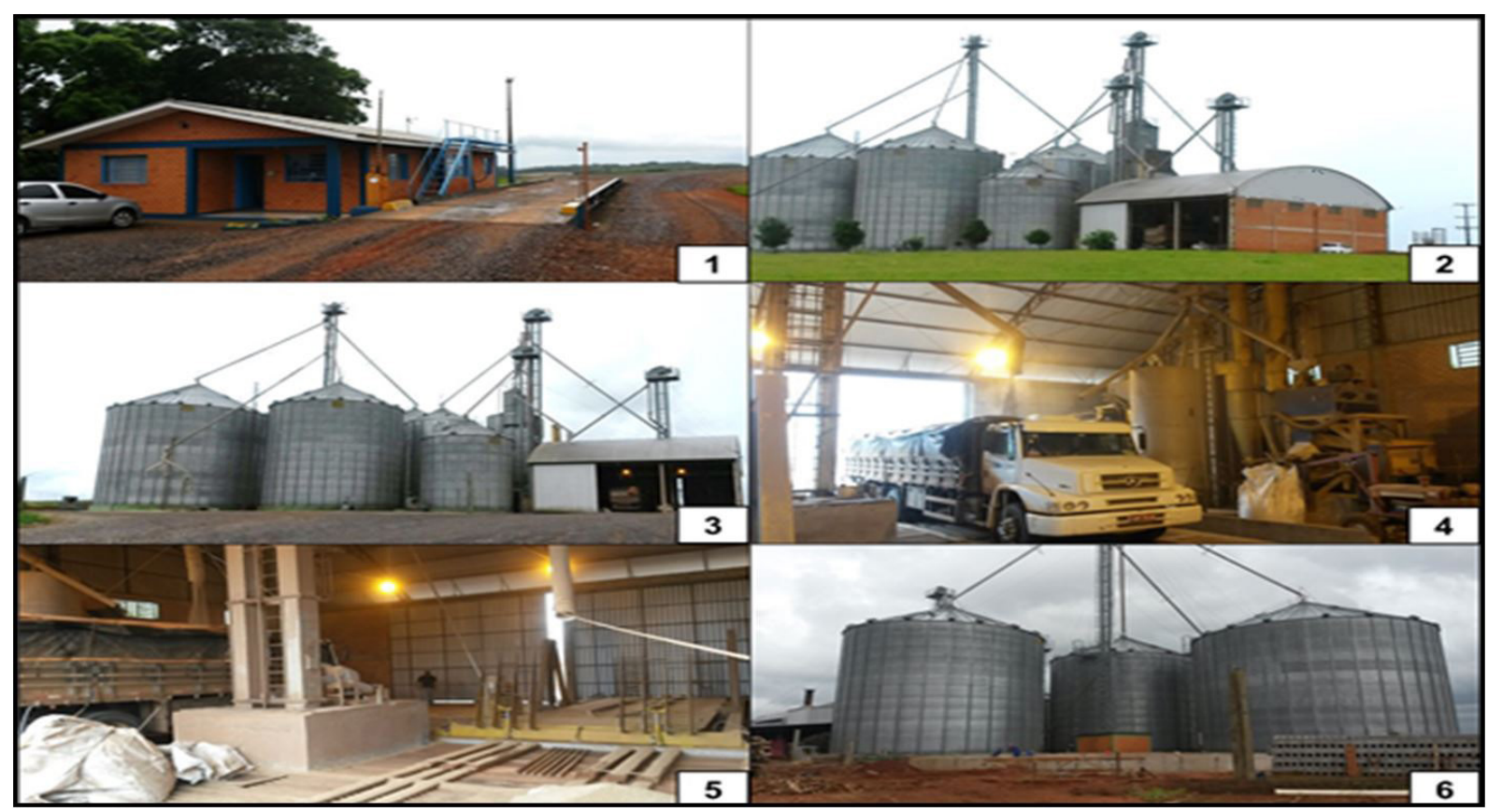

Fonte: Esta pesquisa.

(5) vista geral do galpão, com destaque para a moega; e (6) ampliação do Condomínio de Armazém Rural com a construção de um novo silo.

Com base nas fotos apresentadas do Condomínio de Armazém Rural A, vale ressaltar a foto número 6 . Ela evidencia um aspecto-chave desse modelo e que confirma a maior facilidade que os condôminos têm para realizar ampliações na capacidade estática de armazenagem, já que o investimento será distribuído e diluído equitativamente entre todos os sócios do condomínio, bem como toda estrutura é um bem dos sócios, portanto, ocorre o retorno do investimento.

Além disso, no momento de criação e implementação física de um Condomínio de Armazém Rural, é importante observar algumas características importantes conforme ressaltado pelos entrevistados e observado nas visitações dos três condomínios, tais quais: (a) primeiramente é escolhido e comprado pelos sócios um terreno plano com facilidades burocráticas de aproximadamente seis hectares de área para comportar a estrutura completa de armazenagem e possíveis ampliações no futuro; (b) a escolha do local de instalação do condomínio deve ser estratégica para todos os sócios, isto é, próximo à área agrícola de todos os condôminos e próximo à uma rodovia para facilitar o escoamento da produção; (c) a estrutura deve se localizar em área rural, de preferência longe de moradores e vizinhos para evitar incômodos, como barulhos e poeira.

A Figura 3 ilustra as características apresentadas anteriormente.

Conforme Figura 3, verifica-se praticamente a mesma composição esquematizada na Figura 2, bem como algumas características importantes para a instalação e localização estratégica do empreendimento, como a rodovia pavimentada localizada logo na entrada do empreendimento, área disponível para futuras ampliações e proximidade com área agrícola dos sócios. Tal localização estratégica, principalmente quanto à proximidade com a rodovia e a área agrícola dos sócios, gera redução de perdas de produtos e dos custos logísticos de distribuição, no que se refere às atividades de armazenagem e do transporte. Já que a estrutura de armazenagem é de propriedade dos produtores rurais e o trajeto percorrido até o local de armazenagem é mínimo, estas vantagens podem ser obtidas.

Vale lembrar, conforme ressaltado na revisão da literatura, que a armazenagem pode representar custo de $21 \%$ a $40 \%$ em relação ao custo logístico total, estando apenas atrás dos custos de transportes, que podem representar até $64 \%$ do custo logístico total 
Figura 3. Imagem de satélite do Condomínio de Armazém Rural (A)

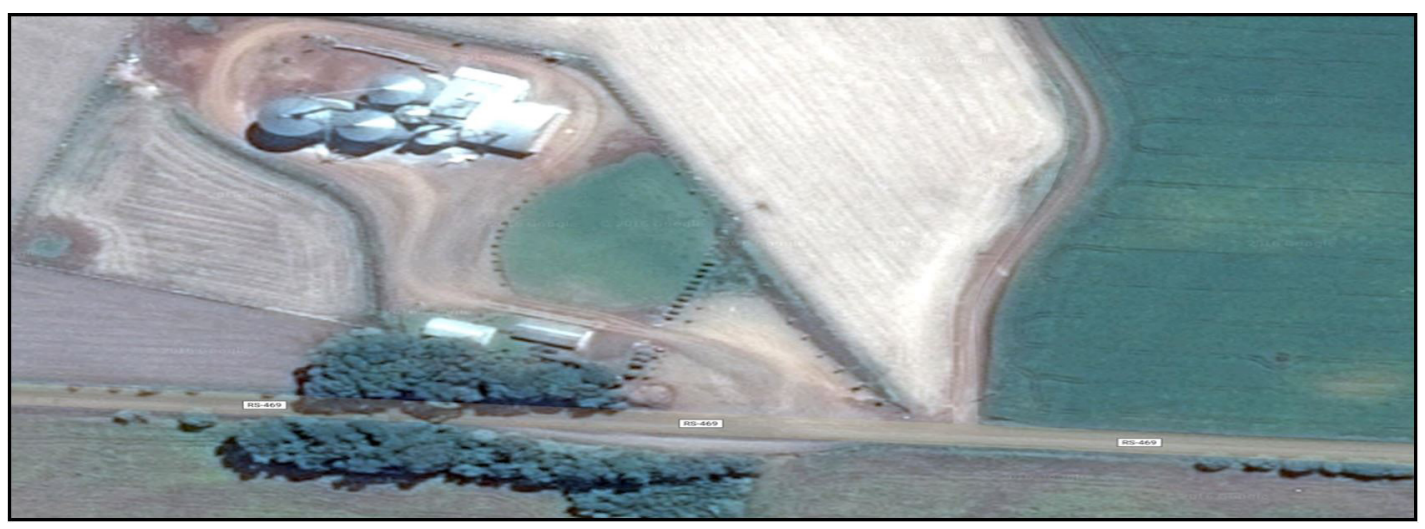

Fonte: Google Maps (2016).

(Ballou, 2011; Figueiredo et al., 2003). Dessa forma, identificar a geração desses custos e saber reduzi-los gerará vantagem competitiva aos produtores rurais, e o modelo condominial permite isso.

Por fim, torna-se importante discutir outros dois aspectos importantes dos Condomínios de Armazéns Rurais, a divisão do patrimônio do empreendimento e os descontos percentuais efetuados no condomínio. A divisão do patrimônio de um Condomínio de Armazém Rural é realizada no momento de criação do empreendimento e baseada na quantidade e área de terras que cada produtor condômino possui, isto é, a estrutura do condomínio será dividida em cotas distintas para cada produtor rural conforme o tamanho da sua propriedade agrícola. Conforme denota a fala do entrevistado C:

Isso foi feito antes de definida a obra, porque são cotas distintas, de acordo com a área explorada de cada um. Então, nós, antes da constituição do condomínio, nas reuniões que antecederam isso, fizemos o total de área explorada, que todos os participantes exploravam e dai cada um entrou com um percentual correspondente à sua participação. Então, há cotas de 2\% até de 16\% (entrevistado C do Condomínio C).

Além disso, o planejamento para construir o Condomínio de Armazém Rural, os silos e os armazéns, e quanto este disponibilizará da capacidade estática para armazenar a produção são baseados na produção e na necessidade de armazenamento que cada produtor possui, além disso, considera-se a possibilidade de ampliação conforme a necessidade. A Tabela 2 exemplifica a divisão patrimonial.

Observa-se na Tabela 2 que, quanto maior a área do produtor, maior será o percentual que lhe é reservado
Tabela 2. Divisão dos bens do Condomínio de Armazém Rural C

\begin{tabular}{cc}
\hline Produtor rural & $\begin{array}{c}\text { Proporção de cada } \\
\text { condômino no condomínio }\end{array}$ \\
\hline Condômino 01 & $15,81 \%$ \\
Condômino 02 & $15,81 \%$ \\
Condômino 03 & $10,01 \%$ \\
Condômino 04 & $10,01 \%$ \\
Condômino 05 & $9,64 \%$ \\
Condômino 06 & $7,91 \%$ \\
Condômino 07 & $6,02 \%$ \\
Condômino 08 & $5,27 \%$ \\
Condômino 09 & $5,27 \%$ \\
Condômino 10 & $4,22 \%$ \\
Condômino 11 & $3,16 \%$ \\
Condômino 12 & $2,65 \%$ \\
Condômino 13 & $2,11 \%$ \\
Condômino 14 & $2,11 \%$ \\
\hline
\end{tabular}

Fonte: Esta pesquisa.

para armazenar sua produção no silo ou armazém do condomínio, bem como do patrimônio que lhe é de direito, o qual dificilmente será vendido ou repassado a alguém sócio ou pessoa de fora, conforme apontado pelos entrevistados durante as entrevistas.

Já os descontos percentuais efetuados pelo condomínio são convertidos em receitas para o próprio condomínio, que poderão ser usadas para benfeitorias no empreendimento, pagamento de despesas e contas, ampliações ou distribuídos entre os próprios sócios. Tais descontos são de dois tipos. O primeiro se refere à taxa de umidade e impureza do produto, que é padronizada 
em tabelas e estipulada pelo condomínio. Já o segundo desconto é próprio do condomínio, chamado de "taxa condominial" ou "taxa administrativa". Essa "taxa administrativa" é um percentual descontado de cada condômino no momento que ele entrega seu produto ao condomínio, sendo que esse percentual descontado pode variar de um condomínio para outro, conforme critérios estabelecidos, e tem por finalidade arcar com as despesas que são geradas pelo condomínio, como pagamento de funcionários, contas, pagamento de parcela do financiamento dos silos etc.

A Tabela 3 apresenta os descontos relativos aos condôminos quanto à taxa condominial.

Percebe-se que cada condomínio tem a sua própria taxa condominial e essa taxa pode ser diferente para cada tipo de produto que chega ao condomínio para ser armazenado, bem como ela pode sofrer reajustes ou modificações caso o condomínio verifique necessidade

Tabela 3. Percentuais descontados em cada Condomínio de Armazém Rural

\begin{tabular}{cccc}
\hline $\begin{array}{c}\text { Taxa } \\
\text { Condominial }\end{array}$ & $\begin{array}{c}\text { Condomínio } \\
\text { A }\end{array}$ & $\begin{array}{c}\text { Condomínio } \\
\text { B }\end{array}$ & $\begin{array}{c}\text { Condomínio } \\
\text { C }\end{array}$ \\
\hline Soja & $2,5 \%$ & $2 \%$ & $2 \%$ \\
Milho & $3,5 \%$ & $2 \%$ & $2 \%$ \\
Trigo & $3,5 \%$ & $2 \%$ & $2 \%$ \\
Aveia & - & $2 \%$ & - \\
\hline
\end{tabular}

Fonte: Esta pesquisa. de variação. No Condomínio A, as taxas condominiais são diferentes para cada tipo de produto, sendo que, para a soja, o desconto é de 2,5\%; para o milho, o desconto é de 3,5\% e, para o trigo, o desconto é de 3,5\%. Já para os outros dois condomínios, os percentuais descontados são os mesmos para todos os produtos, sendo $2 \%$ o desconto que é aplicado para a carga que chega ao Condomínio B e ao Condomínio $C$.

Adicionalmente, deste modelo condominial e das diferenças relativas em relação à taxa condominial ser igual ou diferente para os produtos é devido ao modelo de gestão diferenciar e ser próprio de cada condomínio. Assim, um modelo de gestão torna-se ferramenta estratégica para o empreendimento à medida que busca maximizar o lucro e desenvolver as diferentes atividades do negócio de forma plena e eficaz, gerando, assim, diferencial competitivo diante dos concorrentes.

\subsection{Vantagens dos Condomínios de Armazéns Rurais}

Observou-se que os Condomínios de Armazéns Rurais proporcionam inúmeras vantagens relacionadas ao modelo condominial e ao modelo de armazenagem. Dessa forma, e para melhor compreensão, elas foram categorizadas em ordem de natureza, sendo: econômica, logístico-econômica, social e de comercialização.

Na Tabela 4 são apresentadas as principais vantagens de natureza econômica e logística.

Tabela 4. Vantagens de natureza econômica e logística

\begin{tabular}{|c|c|c|c|c|}
\hline & Tipo de vantagem ou benefício & Condomínio A & Condomínio B & Condomínio C \\
\hline \multirow{7}{*}{ 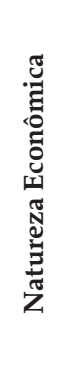 } & Redução de custo & Sim & Sim & Sim \\
\hline & Aumento do lucro & Sim & Sim & Sim \\
\hline & Maior agregação de valor ao produto & Sim & Sim & Sim \\
\hline & Maior rentabilidade sobre a produção & Sim & Sim & Sim \\
\hline & $\begin{array}{l}\text { Facilidade de acesso a novas tecnologias e modernização do } \\
\text { empreendimento }\end{array}$ & Sim & Sim & Sim \\
\hline & Inserção em economias de larga escala & Não & Sim & Sim \\
\hline & Incentivo a empreendimentos para aumento da eficiência da produção & Sim & Sim & Não* \\
\hline \multirow{3}{*}{ 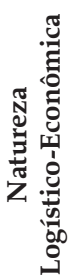 } & Economia com transporte e frete & Não & Sim & Sim \\
\hline & Redução de custo com transporte & Não & Sim & Sim \\
\hline & Redução de filas em cooperativas e armazéns de terceiros e empresas & Sim & Sim & Sim \\
\hline
\end{tabular}

Fonte: Esta pesquisa.

* Entrevistado ficou em dúvida. 
Os entrevistados foram unânimes ao afirmar que, praticamente todos os Condomínios de Armazéns Rurais consideram sete tipos de vantagens, sendo que "maior agregação de valor ao produto" foi citada pelo entrevistado $\mathrm{C}$ como uma das principais, visto que os condomínios padronizam os produtos antes de iniciar o plantio, escolhendo variedades com alta qualidade e sanidade, obtendo, dessa forma, um produto superior e mais valorizado no mercado.

Além disso, a redução de custos, aumento do lucro e maior rentabilidade sobre a produção são vantagens consideradas importantes para esse novo tipo de empreendimento, pois se verifica que os Condomínios de Armazéns Rurais estão obtendo retorno financeiro favorável aos associados. Esse fato não seria observado de forma tão positiva se eles não participassem de algum modelo associativista ou na forma de Condomínio Rural.

Adicionalmente, com base na Tabela 4, o modelo de Condomínio Rural proporciona a redução de custos para os condôminos, no sentido de: (a) economia com transporte e fretes, situação que pode ser mais custosa em épocas de safra, pela falta de caminhões no mercado e aumento do preço dos fretes, ou seja, existe maior procura pelo serviço de transporte e baixa disponibilidade deste, devido à maior demanda provocada pela grande quantidade de produto disponível no mercado e que necessita de escoamento; (b) redução de custo com transporte no sentido de que os produtores são todos vizinhos e geralmente possuem caminhões próprios que não precisam percorrer longas distâncias, bem como os condôminos são responsáveis em levar o produto do campo até o condomínio, sendo que o percurso até o seu destino final é de responsabilidade do comprador (trajeto que haverá maior custo logístico); (c) redução de filas em cooperativas, cerealistas e armazéns de terceiros no sentido de ter de esperar para entregar a produção nesses locais, o que gera menor produtividade no campo, pois o caminhão fica parado em outro local e a colheita fica aguardando o retorno do caminhão; e (d) aquisição de insumos por um melhor preço, já que o volume solicitado é maior e o grupo consegue descontos e melhores prazos.

Quanto aos outros três aspectos, facilidade de acesso a novas tecnologias e modernização do empreendimento, inserção em economias de larga escala e incentivo a empreendimentos para aumento da eficiência da produção, cabe ressaltar que são vantagens próprias do modelo de Condomínio Rural, no sentido de que existe uma relação social benéfica entre os sócios, como a troca de experiências, investimento em inovação e adoção de novas tecnologias no campo (como pivôs) para aprimorar e aumentar a produtividade, a fim de tornar o negócio mais competitivo de forma a possibilitar a inserção em economias de larga escala.

Percebe-se, desses itens, que os condomínios buscam atualização constante em inovação e em novas tecnologias visando o aumento da eficiência produtiva e competitividade. Na Tabela 5 são apresentadas as principais vantagens de natureza social.

Com base na Tabela 5, percebe-se que a organização do tipo Condomínio Rural gera diversas vantagens do tipo social, já que o condomínio é um grupo menor de pessoas e o convívio e trabalho em equipe possibilitam que os sócios discutam sobre diversos aspectos, troquem ideias e experiências, obtenham crescimento coletivo, cooperando a fim de obter maiores oportunidades e chances de sucesso.

Tabela 5. Vantagens de natureza social

\begin{tabular}{|c|c|c|c|c|}
\hline & Tipo de vantagem ou benefício & Condomínio A & Condomínio B & Condomínio C \\
\hline \multirow{6}{*}{$\begin{array}{c}\text { Natureza } \\
\text { Social }\end{array}$} & $\begin{array}{l}\text { Possibilidade para o produtor investir na agricultura } \\
\text { (a formação do grupo torna mais fácil a administração do } \\
\text { empreendimento) }\end{array}$ & Sim & Sim & Sim \\
\hline & $\begin{array}{l}\text { Geração de empregos (contratação de funcionários em } \\
\text { picos de safra ou para o funcionamento do condomínio) }\end{array}$ & Sim & Sim & Sim \\
\hline & Maior acesso às condições de financiamento & Não & Não & Não \\
\hline & Fortalecimento da atividade & Sim & Sim & Sim \\
\hline & Possibilidade de enfrentar crises & Sim & Sim & Sim \\
\hline & Organização menos burocrática & Sim & Sim & Sim \\
\hline
\end{tabular}

Fonte: Esta pesquisa 
As vantagens sociais podem ser observadas na fala do entrevistado B (Condomínio B):

Como a gente é um grupo, a gente se reúne bastante, conversa sobre lavoura, troca bastante ideia. Na prática, realmente, muito mais do que quando a gente tá em empresa e conhece o dia a dia do produtor e a gente vai se ajeitando do que tem de melhor, de pior, que tá dando certo, a gente já vê ali, né?

Além disso, a formação do grupo torna mais fácil a administração de um empreendimento desse porte, possibilitando que haja uma divisão das tarefas entre os condôminos, contratação de funcionários, além de possibilitar que o produtor condômino tenha mais tempo para investir na agricultura e no aprimoramento. Ademais, viabiliza a formação de um empreendimento desse porte quanto à contratação de funcionários e demais despesas, pois, como existem mais sócios envolvidos no negócio, há uma diluição dos custos entre todos. Dessa forma, em vez de existir um funcionário para cada condômino, o que é inviável e custoso para cada produtor rural individualmente, existe a viabilidade de ter um funcionário para todos os condôminos. Assim, o modelo de Condomínio Rural viabiliza financeiramente o compartilhamento de funcionários para trabalhar no empreendimento, além do fato de que os gastos são divididos dentre todos os condôminos.

Percebe-se também que o Condomínio Rural gera um fortalecimento considerável da atividade e possibilita que os produtores tenham condições de enfrentar possíveis crises. Em adição a esse aspecto, denotou-se que um empreendimento do tipo Condomínio de Armazém Rural é uma organização menos burocrática. $\mathrm{O}$ funcionamento e a execução, junto às regras e procedimentos, são menos complexos do que outras formas de organização rural. A estrutura administrativa e gestão são mais simples se comparados a uma cooperativa, e as atividades são mais básicas, tornando os Condomínios de Armazéns Rurais um empreendimento de fácil criação, implantação e execução viável para esse perfil de produtores rurais.

$\mathrm{Na}$ Tabela 5, ressalta-se outro aspecto que merece discussão, referente às condições de financiamento. Os três entrevistados afirmaram que a organização do tipo Condomínio de Armazém Rural não gera vantagem de maior acesso às condições de financiamento, fato que foi contrário ao identificado no referencial teórico.

Essa resposta divergente deve-se em função de que o processo para que se obtenha o financiamento é burocrático e não há diferença no processo entre encaminhamentos de proposta individualizadas ou em grupo. O que facilita a análise do crédito é que o conjunto dos produtores rurais terá mais garantias (bens para viabilizar o financiamento do Condomínio), a fim de conseguir honrar os compromissos junto às instituições financeiras nas quais foi concedido o crédito. Dessa forma, a solicitação de crédito em grupo tem mais vantagens do que individualmente.

Finalmente, são apresentadas na Tabela 6 as vantagens sobre a comercialização dos produtos nos Condomínios de Armazéns Rurais.

Sobre a comercialização foram identificadas mais três vantagens para os produtores rurais que fazem parte de um Condomínio de Armazém Rural: possibilidade de vender o produto em qualquer período do ano (safra ou entressafra); benefício na classificação do grão no momento da comercialização e inserção num ambiente competitivo de mercado.

A inserção num ambiente competitivo de mercado já foi discutida anteriormente em questões econômicas. Porém, essa característica se enquadra também em questões de comercialização no sentido de ter um produto com mais qualidade e mais valorizado no mercado, com menor custo de produção. Assim, a comercialização de um

Tabela 6. Vantagens sobre a comercialização

\begin{tabular}{|c|c|c|c|c|}
\hline & Tipo de vantagem ou benefício & Condomínio A & Condomínio B & Condomínio $\mathrm{C}$ \\
\hline \multirow{3}{*}{ 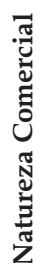 } & $\begin{array}{l}\text { Possibilidade de vender o produto em qualquer período do } \\
\text { ano (safra ou entressafra) }\end{array}$ & Sim & Sim & Sim \\
\hline & Benefício na classificação do grão no momento da comercialização & Sim & Sim & Sim \\
\hline & Inserção num ambiente competitivo de mercado & Sim & Sim & Sim \\
\hline
\end{tabular}

Fonte: Esta pesquisa 
produto nesse padrão, proveniente de um Condomínio de Armazém Rural, terá maior procura no mercado e sua venda será facilitada.

Já o benefício na classificação do grão refere-se à padronização do grão entre os condôminos. Antes de iniciar o plantio, os condôminos escolhem as melhores variedades e de produtividade alta para plantar. Isto gera um produto de maior valor agregado, valorizado no mercado e evita que descontos sejam efetuados no momento de entrega da produção dentro do Condomínio relativos à umidade e qualidade do grão.

E por fim, foi identificado que os condôminos têm a possibilidade de vender o produto em qualquer época do ano, safra ou entressafra. Isso possibilita que os produtores façam a venda do seu produto quando o preço do produto está mais elevado no mercado ou quando eles precisarem vender o produto, o que se constitui como uma vantagem estratégica de comercialização.

Além disso, a venda e comercialização estratégica só são possíveis, pois os silos e armazéns são próprios e não existe tempo máximo para deixar o produto armazenado. Além disso, não existe necessidade de rotatividade de produto entre diversos produtores. Quando um produtor colhe seu produto, ele pode deixá-lo pelo tempo que julgar necessário no armazém ou silo, aguardando o melhor momento para comercializá-lo. Essa situação é diferente da que é percebida em silos e armazéns de terceiros que não dispõem de espaço e tempo suficiente para armazenar o produto de vários produtores rurais.

Essa vantagem também só é possível considerando que os Condomínios são projetados para armazenar a produção de todos os condôminos, além do fato de que podem passar por expansões a fim de aumentar a capacidade estática de armazenagem conforme haja necessidade. Assim, não há déficit de armazenagem nos Condomínios de Armazéns Rurais e eles podem ser expandidos.

Por fim, foram identificadas mais algumas vantagens dos Condomínios de Armazéns Rurais, como: (i) eliminação do atravessador no momento da comercialização do produto, visto que é o próprio produtor ou condomínio que negociam diretamente com o comprador, gerando, assim, um lucro maior ao eliminar a figura do intermediário que teria algum ganho em cima do produtor para efetuar a venda, ganho esse que volta para o próprio produtor; (ii) diminuição dos custos de transação; (iii) integração com o mercado; (iv) maior agilidade para entregar o produto (como o armazém/silo é próprio, o produtor não pega mais fila para armazenar a produção e nem fica mais esperando o caminhão retornar para continuar a colheita); (v) tranquilidade para entregar a produção e nas atividades do empreendimento (divisão das tarefas entre os condôminos); (iv) viabilidade financeira (silo/armazém próprios) e social dos condôminos (amizade, conversas, integração, conhecimento e aprendizado, troca de experiências); e (vii) maior segurança, satisfação pessoal e facilidade com o trabalho (vários produtores que se ajudam).

Portanto, essa categoria atingiu o objetivo de caracterizar a estruturação dos Condomínios de Armazéns Rurais já consolidados nos estados do Paraná e Rio Grande do Sul e complementar a identificação das suas vantagens (Quadro 1).

Destacam-se, conforme o Quadro 1, dentre as principais vantagens: (i) maior agregação de valor ao produto; (ii) redução de custos logísticos, de produção e de gargalos logísticos; (iii) aumento do lucro; (iv) aquisição de insumos por preço melhor; (v) facilidade de acesso às condições de financiamento; (vi) fortalecimento da atividade; (vii) possibilidade de vender o produto em qualquer período do ano; (viii) inserção num ambiente competitivo de mercado; (ix) eliminação do atravessador no momento da comercialização do produto e (x) viabilidade financeira (silo/armazém próprios) e social dos condôminos.

\subsection{Desafios para os Condomínios de Armazéns Rurais}

Constatou-se que o modelo de Condomínio de Armazém Rural proporciona diversas vantagens ao produtor rural e ao produto agrícola e facilita o escoamento da produção agrícola, além de resolver alguns problemas logísticos que podem causar perdas e, consequentemente, diminuir a competitividade da atividade.

Contudo, é importante apontar alguns desafios que foram identificados e que podem surgir ao longo do tempo ou em função do próprio sistema. Tais desafios serão tratados como aspectos que merecem atenção especial para esse tipo de empreendimento, a fim de que sejam gerenciados e minimizados para não comprometerem o funcionamento e sucesso dos condomínios. O Quadro 2 resume esses desafios: 
Quadro 1. Principais vantagens dos Condomínios de Armazéns Rurais

\begin{tabular}{|c|}
\hline (i) maior agregação de valor ao produto; \\
\hline (ii) redução de custo; \\
\hline (iii) aumento do lucro; \\
\hline (iv) maior rentabilidade sobre a produção; \\
\hline (v) economia com transporte e fretes; \\
\hline (vi) redução de custos logísticos; \\
\hline (vii) aquisição de insumos por um melhor preço; \\
\hline (viii) facilidade de acesso a novas tecnologias e modernização do empreendimento; \\
\hline (ix) possibilidade para o produtor investir na agricultura (a formação do grupo torna mais fácil a administração do empreendimento); \\
\hline (x) geração de empregos; \\
\hline (xi) facilidade de acesso às condições de financiamento; \\
\hline (xii) fortalecimento da atividade; \\
\hline (xiii) possibilidade de enfrentar crises; \\
\hline (xiv) organização menos burocrática; \\
\hline (xv) possibilidade de vender o produto em qualquer período do ano (safra ou entressafra); \\
\hline (xvii) benefício na classificação do grão no momento da comercialização; \\
\hline (xviii) inserção num ambiente competitivo de mercado; \\
\hline (xix) eliminação do atravessador no momento da comercialização do produto; \\
\hline (xx) diminuição dos custos de transação; \\
\hline (xxi) integração com o mercado; \\
\hline $\begin{array}{l}\text { (xxii) maior agilidade para entregar o produto (como o armazém/ silo é próprio, o produtor não pega mais fila para armazenar } \\
\text { a produção e nem fica mais esperando o caminhão retornar para continuar a colheita); }\end{array}$ \\
\hline (xxiii) tranquilidade para entregar a produção e nas atividades do empreendimento (divisão das tarefas entre os condôminos); \\
\hline $\begin{array}{l}\text { (xxiv) viabilidade financeira (silo/armazém próprios) e social dos condôminos (amizade, conversas, integração, conhecimento } \\
\text { e aprendizado, troca de experiências); }\end{array}$ \\
\hline
\end{tabular}

Fonte: Esta pesquisa.

Quadro 2. Principais desafios dos Condomínios de Armazéns Rurais

(i) podem ser emitidas várias notas e não apenas uma para efetivar a venda em grupo (mais procedimentos burocráticos);

(ii) mais responsabilidade com o empreendimento;

(iii) maior atenção quanto à gestão e ao funcionamento do condomínio;

(iv) o relacionamento interpessoal entre os condôminos pode gerar desentendimento e interferir no andamento das atividades; (v) corrupção (desvios).

Fonte: Esta pesquisa.

Destacam-se, com base no Quadro 2: (i) gestão, administração e funcionamento do condomínio; (ii) relacionamento interpessoal entre os condôminos e (iii) possíveis desvios. Quanto ao primeiro ponto, os entrevistados afirmaram que existe maior responsabilidade com o empreendimento quanto à administração, gestão e funcionamento. Isso ocorre porque o empreendimento é um bem de todos e, para garantir o bom funcionamento do estabelecimento, as atividades passam a ser desempenhadas e de responsabilidade de todos os sócios.
Do segundo item, o relacionamento interpessoal, os condôminos relataram que isso pode gerar algum desentendimento e interferir no andamento das atividades. Dessa forma, os entrevistados disseram que, no momento de criação do condomínio, a escolha dos sócios que farão parte do empreendimento deve ser entre produtores com bom relacionamento entre si, de preferência que se conheçam, e que compartilhem de ideias e objetivos semelhantes. 
Por último, figura o item sobre possíveis desvios que possam acontecer no condomínio. Dessa forma, é importante que existam boas práticas e transparência entre todos os condôminos para evitar que isso ocorra, além de buscar o bem para todos de forma justa.

Vale ressaltar, ainda, que os prontos encontrados nesse item corroboram e complementam com ideias de alguns autores acerca do tema Condomínios Rurais quanto aos aspectos negativos ou de insucesso deles, como: a inadimplência que pode existir entre os condôminos (Gullo, 2001); a instabilidade e o fraco desempenho dos condôminos (Olivo, 2000); falhas e problemas de gestão (Olivo, 2000; Moyano-Estrada \& Anjos, 2001; Hespanhol, 2009); carência de estudos de mercados e de viabilidade econômica (Gullo, 2001) e falta de consenso entre os associados (Garrido \& Sehnem, 2006).

\subsection{Agenda de Pesquisa: Condomínios de Armazéns Rurais}

Por fim, com base na pesquisa empírica e revisão da literatura realizadas, são apresentadas sugestões de trabalhos futuros em relação à temática dos Condomínios de Armazéns Rurais, que se constituem em temas de estudos potenciais:

(a) Analisar as perspectivas de implementação de condomínios em regióes notoriamente grande produtoras de grãos, como a região Centro-Oeste com base na opinião de especialistas e produtores rurais;

(b) Quantificar o valor das cotas que cada condômino possui nos Condomínios de Armazéns Rurais, visto que essa é uma das lacunas identificadas no presente estudo, em que os condôminos não sabem quantificar o valor exato por meio da valorização do empreendimento com o passar dos anos;

(c) Identificar a localização ótima de Condomínios de Armazéns Rurais para o RS e outros estados brasileiros através de modelagem matemática;

(d) Propor um modelo matemático de localização ótima para os Condomínios de Armazéns Rurais para os estados brasileiros com potencial;

(e) Propor um modelo matemático de roteirização de cargas a partir dos Condomínios de Armazéns Rurais que tenha como objetivo minimizar os custos logísticos até exportação; (f) Analisar a decisão de implementar um Condomínio de Armazém Rural, comparando-se com outra forma de associação ou demais alternativas, com base na Abordagem Multicritério de Apoio à Decisão;

(g) Propor uma metodologia para comparar os custos logísticos dos Condomínios de Armazéns Rurais com outras formas de armazenagem, como cooperativa ou cerealista;

(h) Propor uma metodologia de rotas de escoamento de Condomínios de Armazéns Rurais da região Sul do País para minimizar custos;

(i) Quantificar qual o valor dos custos logísticos que foram economizados após a criação e funcionamento dos Condomínios de Armazéns Rurais;

(j) Mapear e identificar todos os Condomínios de Armazéns Rurais existentes no território brasileiro;

(k) Utilizar os procedimentos técnicos survey ou grupo focal com todos os condôminos e profissionais que conhecem o modelo, acerca de características, ações ou opiniões dos Condomínios de Armazéns Rurais em termos nacionais, com um público que conheça o modelo, a fim de descobrir novos resultados;

(1) Realizar uma revisão sistemática de literatura em âmbito internacional sobre o tema de Condomínios de Armazéns Rurais, utilizando o protocolo do Methodi Ordinatio, proposto por Pagani et al. (2015);

(m) Analisar os dados coletados desse artigo sobre Condomínios de Armazéns Rurais com o uso do software NVivo;

(n) Identificar o potencial de implementação e expansão de Condomínios Rurais para outras culturas e negócios agrícolas;

(o) Realizar a análise da viabilidade econômico-financeira de outros Condomínios Rurais agrícolas;

(p) Propor o uso de outra metodologia de viabilidade econômica para os Condomínios de Armazéns Rurais;

(q) Relacionar os Condomínios de Armazéns Rurais com o sistema de agendamento de portos quanto ao escoamento da produção agrícola e vantagens que os condomínios podem trazer para o mesmo;

(r) Analisar a organização dos Condomínios de Armazéns Rurais sob a ótica da Teoria dos Custos de Transação; 
(s) As informações buscadas no banco de dados da Conab sobre armazenagem não citam/diferenciam em seu sistema de classificação os Condomínios Rurais. Apenas há uma divisão em tipo de entidade quanto à cooperativa, privada e oficial. Dessa forma, sugere-se propor uma reestruturação no sistema de classificação sobre armazenagem descrevendo todos os Condomínios de Armazéns Rurais do País;

(t) Realizar um estudo, por meio da técnica Delphi, junto aos entrevistados dos condomínios, sobre as vantagens e benefícios dos Condomínios de Armazéns Rurais, colocando pesos (notas) em todos os critérios/itens identificados nesta pesquisa;

(u) Aprofundar e realizar um estudo sobre a discussão do conceito em si de Condomínios Rurais, sobre as teorias no âmbito das organizações na forma de Condomínio Rural e sobre a gestão dos diferentes tipos de Condomínios Rurais (armazéns, leiteiros, suínos e de agroenergia);

(v) Discutir, à luz da teoria, o modelo de Condomínios Rurais com outras formas condominiais, como Condomínios Logísticos, Residenciais e Industriais;

(x) Discutir o modelo dos Condomínios Rurais a partir dos estudos de Claude Ménard sobre formas híbridas de governança (Ménard, 2004).

\section{Considerações finais}

Constata-se que a logística agroindustrial brasileira apresenta diversos desafios para o setor de armazenagem, que devem ser vencidos e superados para que não comprometa o crescimento e o desenvolvimento do País em níveis satisfatórios. Os Condomínios de Armazéns Rurais representam uma solução para o setor de armazenagem e para outros gargalos logísticos existentes no País.

Adicionalmente, os Condomínios de Armazéns Rurais diminuem o déficit de armazenagem e outros gargalos logísticos, além de apresentarem inúmeras vantagens, como: a comercialização estratégica da produção, a redução de custos de armazenagem e de custos logísticos e o aumento do lucro.

Percebe-se que os condomínios são um modelo em expansão, viáveis e financeiramente competitivos para o agronegócio brasileiro. Como contribuições desse trabalho denotam-se a oportunidade de novas pesquisas na área, o mapeamento de práticas inovadoras de armazenagem no País, além do apoio à tomada de decisões para os Condomínios de Armazéns Rurais.

Quanto às limitações desse trabalho, foram encontradas dificuldades para obter informações sobre outros Condomínios de Armazéns Rurais da região Sul, e a pesquisa limitou-se no estudo de apenas três condomínios. Dessa forma, sugere-se que seja realizado um levantamento sistemático de todos os Condomínios de Armazéns Rurais da região Sul e do restante do País, além de trabalhos que envolvam modelagem matemática, como a localização ótima dos condomínios para regiões brasileiras com maior déficit de armazenagem, bem como estudos de viabilidade econômica-financeira. Sugerem-se também pesquisas quantitativas, do tipo survey e outras baseadas na abordagem de apoio à decisão multicritério, as quais podem fornecer dados objetivos e sistemáticos desse novo tipo de configuração que surge no agronegócio brasileiro.

\section{Referências}

Almeida, C., Bariccatti, R. A., Frare, L. M., Camargo Nogueira, C. E., Mondardo, A. A., Contini, L., Gomes, G. J., Rovaris, S. A., Santos, K. G., \& Marques, F. (2017). Analysis of the socio-economic feasibility of the implementation of an agroenergy condominium in western Paraná - Brazil. Renewable \& Sustainable Energy Reviews, 75, 601-608.

Alvarenga, A. C., \& Novaes, A. G. (2000). Logística aplicada: suprimentos e distribuição física (3. ed., 194 p.). São Paulo: Edgard Blucher.

Anjos, F. S., Moyano Estrada, E., \& Caldas, N. V. (2011). Family farming and economic cooperation: the emergence and decline of agrarian condominios in Southern Brazil. Journal of Rural Social Sciences, 26(2), 30-51.

Ballou, R. H. (2011). Logística empresarial: transporte, administração de materiais e distribuição física $(\mathrm{H}$. T. Y. Yoshizaki, Trad., 1. ed., 392 p.). São Paulo: Atlas.

Bardin, L. (1977). Análise de conteúdo. Lisboa: Edições 70.

Barreto, R. C. S., \& Almeida, E. (2009). A contribuição da pesquisa para convergência e crescimento da renda agropecuária no Brasil. Revista de Economia e Sociologia Rural, 47(3), 719-737.

Biagi, J. D., Bertol, R., \& Carneiro, M. C. (2002). Armazéns em unidades centrais de armazenamento. In I. Lorini, 
L. H. Miike \& V. M. Scussel (Eds.), Armazenagem de grãos (Cap. 3, pp. 157-174). Campinas: Instituto Bio Geneziz.

Brasil. Ministério da Agricultura Pecuária e Abastecimento - MAPA. Secretaria de Política Agrícola. (2015). Projeções do agronegócio: Brasil 2013/14 a 2023/24. Brasília. Recuperado em 21 de maio de 2015, de http:/ / www.agricultura.gov.br

Brasil. Ministério da Agricultura Pecuária e Abastecimento - MAPA. Secretaria de Política Agrícola. Departamento de Economia Agrícola. Coordenação-Geral de Análises Econômicas. (2017). Estatísticas e dados básicos de economia agrícola. Brasília. Recuperado em 21 de fevereiro de 2017, de www.agricultura.gov.br

Brigatte, H., \& Teixeira, E. C. (2011). Determinantes de longo prazo do produto e da Produtividade Total dos Fatores da agropecuária brasileira no período 1974-2005. Revista de Economia e Sociologia Rural, 49(4), 815-836.

Caixeta-Filho, J. V. (2006). A logística do escoamento da safra brasileira. Piracicaba: CEPEA/USP.

Companhia Nacional de Abastecimento - CONAB. (2017). Série histórica: produção vs capacidade de armazenamento. Brasília.

Ferrari, R. C. (2006). Utilização de modelo matemático de otimização para identificação de locais para instalação de unidades armazenadoras de soja no estado do Mato Grosso (Dissertação de mestrado). Escola Superior de Agricultura "Luiz de Queiroz", Universidade de São Paulo, Piracicaba.

Figueiredo, K. F., Fleury, P. F., \& Wanke, P. (2003). Logística e gerenciamento da cadeia de suprimentos: planejamento do fluxo de produtos e dos recursos. São Paulo: Atlas.

Filippi, A. C. G. (2017). Caracterização e análise da viabilidade de Condomínios de Armazéns Rurais: um estudo multicaso (Dissertação de mestrado). Faculdade de Agronomia e Medicina Veterinária, Universidade de Brasília, Brasília.

Gaban, A. C., \& Guarnieri, P. (2015). Identificação de gargalos na logística agroindustrial: revisão sistemática da literatura. In Anais do 53ํㅡㄹ Congresso da SOBER. Brasília: SOBER.

Gaban, A. C., Silva, F. M., Guarnieri, P., \& Brisola, M. V. (2016). Evolução do agronegócio da produção de grãos e armazenagem: perspectivas do Brasil para 2024/25. In Anais do 54ํㅡㄹ Congresso da SOBER. Brasília: SOBER.

Garrido, L. R., \& Sehnem, S. (2006). Gestão associativa no empreendimento rural. Revista de Administração, 5(8), 65-88.

Gentil, L. V., \& Martin, S. (2014). Armazenagem da produção: é viável para o produtor rural? Revista Agroanalysis, 34(5), 28-29.

Google Maps. (2016). Imagem de satélite de um condomínio de armazém rural. Recuperado em 21 de agosto de 2016, de https://www.google.com.br/maps/ place/Get\%C3\%BAlio+Vargas,+RS /@-27.9457431,-
$52.3837504,298 \mathrm{~m} /$ data $=! 3 \mathrm{~m} 1 ! 1 \mathrm{e} 3 ! 4 \mathrm{~m} 5 ! 3 \mathrm{~m} 4 ! 1 \mathrm{~s} 0 \times 94 \mathrm{e} 2 \mathrm{e} 2865 \mathrm{~d}$ 1af9f3:0x3fcf7331f104b450!8m2!3d-27.8884044!4d-52.2258411

Guarnieri, P., \& Hatakeyama, K. (2010). Formalização da logística de suprimentos: caso das montadoras e fornecedores da indústria automotiva brasileira. Produção, 20(2), 186-199.

Gullo, M. C. R. (2001). Fundo estadual de apoio ao desenvolvimento dos pequenos estabelecimentos ruraisFEAPER: uma análise dos 10 anos, com ênfase no problema da inadimplência (Dissertação de mestrado). Universidade Federal do Rio Grande do Sul, Porto Alegre.

Hespanhol, R. A. M. (2009). O Programa de Aquisição de Alimentos (PAA) na MRG de Dracena (SP). Geo UERJ, 3(20), 64-87.

Martins, R. S., Lobo, D. S., Alves, A. F., \& Sproesser, R. L. (2014). Fatores relevantes na contratação de serviços em terminais intermodais para granéis agrícolas. Revista de Economia e Sociologia Rural, 52(2), 347-364.

Martins, R. S., Rebechi, D., Prati, C. A., \& Conte, H. (2005). Decisões estratégicas na logística do agronegócio: compensação de custos transporte-armazenagem para a soja no Estado do Paraná. Revista de Administração Contemporânea, 9(1), 53-78.

Ménard, C. (2004). The economics of hybrid organizations. Journal of Institutional and Theoretical Economics, 160(3), 345-376.

Ménard, C., \& Klein, P. G. (2004). Organizational issues in the agrifood sector: toward a comparative approach. American Journal of Agricultural Economics, 86(3), 750-755.

Moyano-Estrada, E., \& Anjos, F. S. (2001). New forms of economic cooperation in family agriculture: the case of condominios in Santa Catarina, Brazil. Journal of Rural Cooperation, 29(1), 1-23.

Neves, M. F., \& Conejero, M. A. (2007). Sistema agroindustrial da cana: cenários e agenda estratégica. Economia Aplicada, 11(4), 587-604.

Nogueira Junior, S., \& Tsunechiro, A. (2005). Produção agrícola e infra-estrutura de armazenagem no Brasil. Informações Econômicas, 35(2), 8-18.

Oliveira, A. L. R. (2011). A logística agroindustrial frente aos mercados diferenciados: principais implicações para a cadeia da soja. Informações Econômicas, 41(6), 17-34.

Olivo, C. J. (2000). Sustentabilidade de condominios rurais formados por pequenos agricultores familiares: análise e proposta de modelo de gestão (Tese de doutorado). Universidade Federal de Santa Catarina, Florianópolis.

Olson, M. (1965). The logic of collective action: public goods and the theory of groups. Cambridge: Harvard University Press.

Pagani, R. N., Kovaleski, J. L., \& Resende, L. M. (2015). Methodi Ordinatio: a proposed methodology to select 
and rank relevant scientific papers encompassing the impact factor, number of citation, and year of publication. Scientometrics, 105(3), 2109-2135.

Saes, M. S. M. (2005). Organizações e instituições. In D. Zylbersztajn \& M. F. Neves (Eds.), Economia \& gestão dos negócios agroalimentares (3. reimpr.). São Paulo: Pioneira Thomson Learning.

Sasseron, J. L. (1995). Armazenamento de grãos. In R. A. R. Gomes, M. F. P. M. Castro, S. R. T. Valentini \& S. Bolonhezi (Eds.), Atualização em tecnologia de pós-colheita de grãos (pp. 50-87). Campinas: Instituto de Tecnologia de Alimentos.
Silva, E. L., \& Menezes, E. M. (2001). Metodologia da pesquisa e elaboração de dissertação (3. ed., 121 p.). Florianópolis.

Weil, K. E. (1975). Logística empresarial: uma introdução à administração de transportes. Revista de Administração de Empresas, 15(3), 72-73.

Wenningkamp, K. R., \& Schmidt, C. M. (2016). Ações coletivas no agronegócio: uma análise da produção científica no Brasil a partir de teses e dissertações (19982012). Revista de Economia e Sociologia Rural, 54(3), 413-436.

Zylbersztajn, D. (2017). Agribusiness systems analysis: origin, evolution and research perspectives. Revista de Administração, 52(1), 114-117. 